\title{
Axial Water Ingress MV XLPE Cable Designs with Watertight Barrier
}

\author{
Knut Brede Liland, Svein Magne Hellesø and Sverre Hvidsten \\ Electric Power Technology, SINTEF Energy Research AS, PO Box 4761 Sluppen, \\ NO-7465 Trondheim, Norway \\ Knut.B.Liland@sintef.no \\ Karl Magnus Bengtsson ${ }^{1}$ and Arve Ryen ${ }^{2}$ \\ Nexans Norway AS \\ PO Box 42, NO-1751 Halden, Norway ${ }^{1}$ \\ PO Box 1009, NO-7801 Namsos, Norway ${ }^{2}$
}

\begin{abstract}
Humidity can enter the insulation system when the outer sheath of a cable becomes damaged. The relative humidity can then increase above a critical value $(70 \% \mathrm{RH})$, facilitating initiation and growth of water trees. The purpose of this experimental and numerical work is to determine how fast water vapour will diffuse axially in a soaked cable with a damaged outer sheath.

Before drying (evacuation) relative humidity and temperature sensors were placed within the outer sheath at different axial positions. After the drying process a hole was cut at the cable end facilitating water ingress. Numerical calculations of axial water diffusion were performed using Comsol.

The numerical calculations show that the axial water vapour diffusion in the cable is slow and dependent of the air gap close to the swelling tape. After 430 days the measured humidity at $0.5 \mathrm{~m}$ had increased by about $75 \%$ (initial 20\%), and the sensor at $1 \mathrm{~m}$ had increased by $40 \%$. Numerical calculations show a slower increase in the relative humidity. The actual axial liquid water penetration extensions, is yet not determined. The numerical calculations show that this is an important factor, as the calculations seem to be in more agreement with measurements when adjusting the position of the water front.
\end{abstract}

\section{Introduction}

Relative humidity (RH) above $70 \%$ in XLPE insulation [1] can initiate water treeing. It is therefore important to avoid high relative humidity in the cable and thereby strongly increase the expected service lifetime. Many different materials are used in the water barrier design, e.g. swelling tapes with concentration dependent water vapour absorption and also extremely high liquid water absorption capacity. The swelling tapes are included to avoid axial water ingress after outer sheath damage. After such damage, the liquid water will be absorbed by the tapes by rapid swelling, blocking the water to penetrate further. The distance from the cable damage that this occurs depends on the water pressure at the damaged section. The swelling stops the (capillary) liquid water ingress, but then the water vapour will propagate further along the cable by diffusion in the tiny air gap. The axial diffusion should be examined as it determines the length of the cables on both sides of a failure that should be removed and replaced. The purpose of this paper is therefore to examine the axial diffusion of water vapour in a MV cable after an (artificial) outer sheath damage. The approach includes an experimental and a numerical modelling part.

\section{Theory and Modelling of water ingress}

Theory

The solubility of water $\mathrm{S}$ in a polymeric material is expressed in the following relation:

$$
\rho=S \cdot p
$$

Where $\rho$ is the water content in equilibrium of the polymer and $p$ is the water vapour pressure above the surface of the polymer. This (1) is Henry's Law assuming that the solubility coefficient is independent of the partial pressure. For some materials the solubility coefficient could depend on the partial pressure of water vapour. The solubility coefficient generally also depends on the temperature $T$. The mass flux of water $j$ in a polymer caused by diffusion can usually be assumed to follow Fick's first law [2]:

$$
j=-D \nabla \rho
$$

$D$ is the diffusion coefficient. If the diffusion coefficient is independent of the water concentration in the polymer, the diffusion is called Fickian. The diffusion coefficient can also depend on the temperature.

\section{Numerical modelling}

The time evolution of the axial water concentration in the cable can be found by combining (2) and the continuity equation giving:

$$
\frac{\partial \rho}{\partial t}+\nabla \cdot(-D \nabla \rho)=0
$$




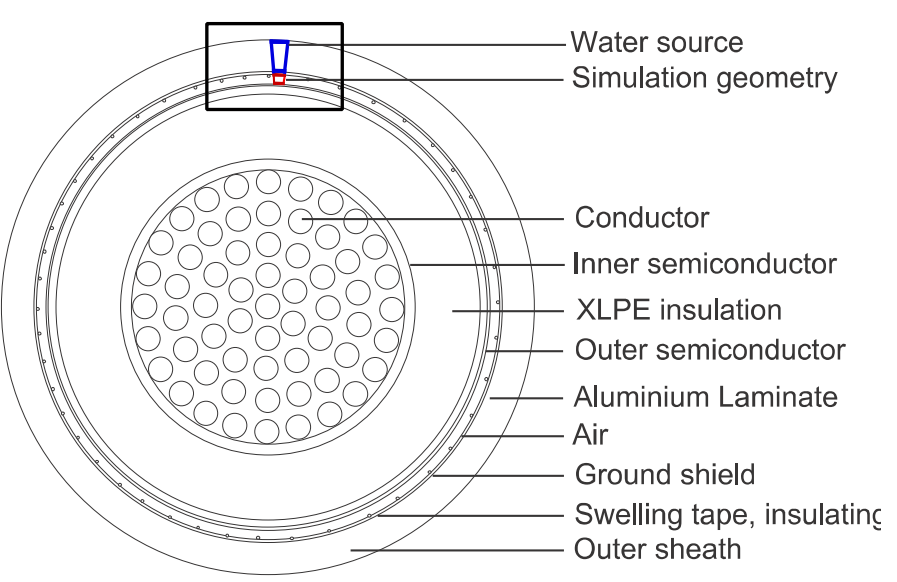

Figure 1: Simulation segment cross section, the black square enlarged in figure 2.

Table 1 presents estimates [4] of the diffusion and solubility coefficient for air and swelling tape. This is used as input for the diffusion calculations. To be able to model numerically and calculate the axial water diffusion into the region between the outer sheath and the cable core, it is necessary to know the solubility and diffusion coefficients at relevant temperatures [3-5]

The solubility coefficient for the swelling tapes is dependent on the water vapor pressure. The sorption characteristics of the swelling tapes have been measured [3] and the measured data could be fitted reasonably well:

$$
S=\frac{b}{1-a \cdot p}
$$

Assuming that the solubility is linearly dependent on the amount of absorbed water $S=a \rho+b$. The parameters used in

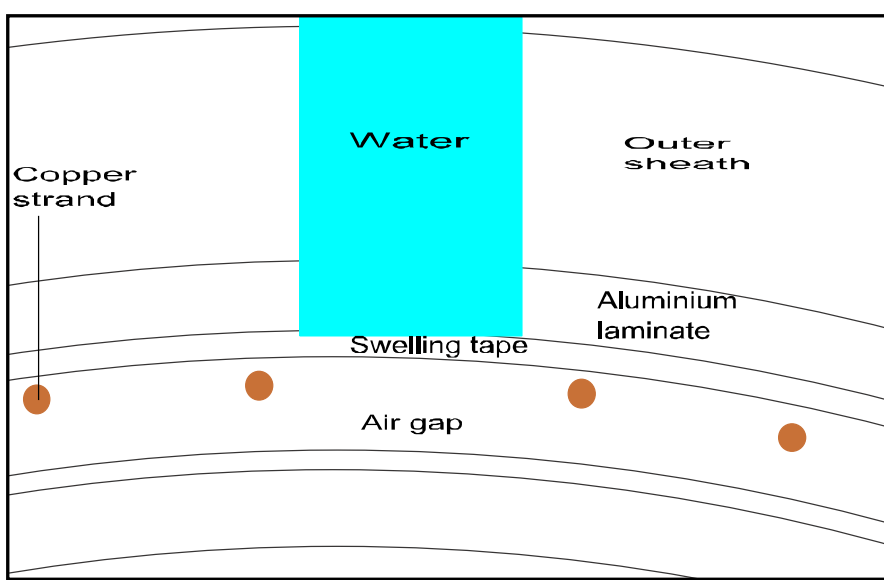

Figure 2: Simulation geometry with the water source in blue, swelling tape and air gap for calculating the axial diffusion of the humidity.

the simulations of the swelling tapes are $a=2.49 \times 10^{-04} \mathrm{~Pa}^{-1}$ and $b=4.33 \times 10^{-02} \mathrm{~kg} /\left(\mathrm{m}^{3} \mathrm{~Pa}\right)$.
The swelling tape and air gap dimensions were measured in a microscope (Figure 3) to be used as input in the model. The thickness of the sheath is assumed to be so small compared to the radius that diffusion of water through the edges can be neglected. The water blocking tapes are in general strongly anisotropic, and therefore these assumptions possibly do not hold for such materials. Therefore diffusion coefficients were derived from the absorption curves which are mean diffusion coefficients over the entire concentration range.

Table 1 Diffusion and Solubility Data at $20^{\circ} \mathrm{C}$ [4]

\begin{tabular}{|c|c|c|c|}
\hline Material & $D\left(\mathrm{~m}^{2} / \mathrm{s}\right)$ & $\mathrm{S}\left(\mathrm{kg} / \mathrm{m}^{3} \mathrm{~Pa}\right)$ & Width \\
\hline Swelling Tape & $3.5 \times 10^{-13}$ & $0.0433^{*}$ & $0.22 \mathrm{~mm}$ \\
\hline Air & $2.4753 \times 10^{-5}$ & $7.3779 \times 10^{-6}$ & $0.44 \mathrm{~mm}$ \\
\hline
\end{tabular}

Table 2 Modelling was done for four cases:

\begin{tabular}{|c|c|c|c|c|c|c|c|c|c|}
\hline \multirow{2}{*}{ Case } & \multicolumn{9}{|c|}{ Volume between insulation screen and outer sheath } \\
\hline & $\begin{array}{l}\text { Air } \\
(\%)\end{array}$ & $\begin{array}{l}\operatorname{Air} \\
(\mathrm{mm})\end{array}$ & $\begin{array}{l}\text { Swelling } \\
\text { tape (\%) }\end{array}$ & $\begin{array}{l}\text { Swelling } \\
\text { tape } \\
(\mathrm{mm})\end{array}$ & \multicolumn{5}{|c|}{$\begin{array}{l}\text { Position of liquid water } \\
\text { from sheath damage }(m)\end{array}$} \\
\hline 1. & 100 & 0.66 & 0 & 0 & \multicolumn{5}{|l|}{0} \\
\hline 2. & 0 & 0 & 100 & 0.66 & \multicolumn{5}{|l|}{0} \\
\hline 3. & 67 & 0.44 & 33 & 0.22 & \multicolumn{5}{|l|}{0} \\
\hline 4. & 67 & 0.44 & 33 & 0.22 & 0 & 0.1 & 0.2 & 0.3 & 0.4 \\
\hline
\end{tabular}

\section{Experimental Work}

A $24 \mathrm{kV}$ XLPE $23 \mathrm{~m}$ long cable with a stranded aluminium conductor $\left(240 \mathrm{~mm}^{2}\right.$, watertight with swelling tape and aluminium laminate water barrier) was used in the experiment.
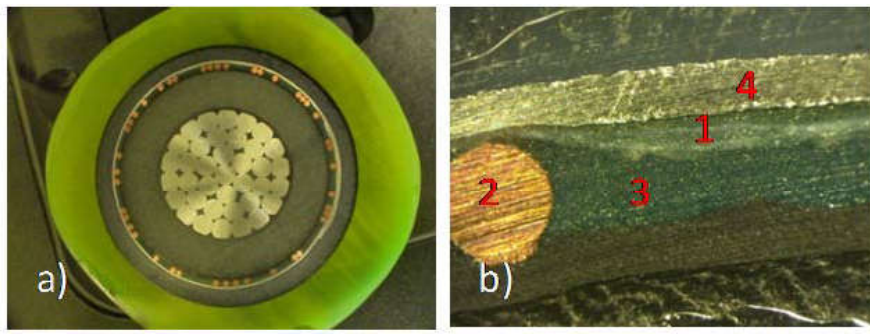

Figure 3: a) Cross section of the cable with epoxy moulded around b) Close-up of swelling tape (1), copper screen strand (2), air gap (3) and aluminium laminate (4).

Several RH and temperature sensors were installed close to the swelling tape through holes cut in the outer sheath and aluminium laminate. The sensors were protected with an aluminium housing, aluminium tape, glue and heat shrinkable glue tubing around (Figure 4) to reduce the amount of moisture entering the cable that could disturb the experiment. The relative humidity and temperature were 
monitored after the installations. The sensors used were calibrated in a climate chamber prior to installation in the cable.

It was found that the cable had a relative humidity of about $60 \%\left(20{ }^{\circ} \mathrm{C}\right)$ before the drying process. Drying was performed by evacuating the gas via the cable ends through vacuum metal connections (Figure 5) sealed with glue inside and with heat shrinkable glue tubing around. The valves for the evacuation tubes were closed and the vacuum pump stopped after the drying period. The sensors were affected by the evacuation and needed to reach equilibrium before the experiment started with a pressure within the outer sheath equal to the ambient pressure.

A hole was cut in one of the cable ends and a water source was installed to facilitate the water leakage (figure 5).

In Table 3 the initial relative humidity values before the water leakage into the cable starts are shown. Note the high ambient relative humidity compared to the relatively dry cable after the evacuation and that the sensors closest to the cable ends near the evacuation hosing seem to be in the driest environment.

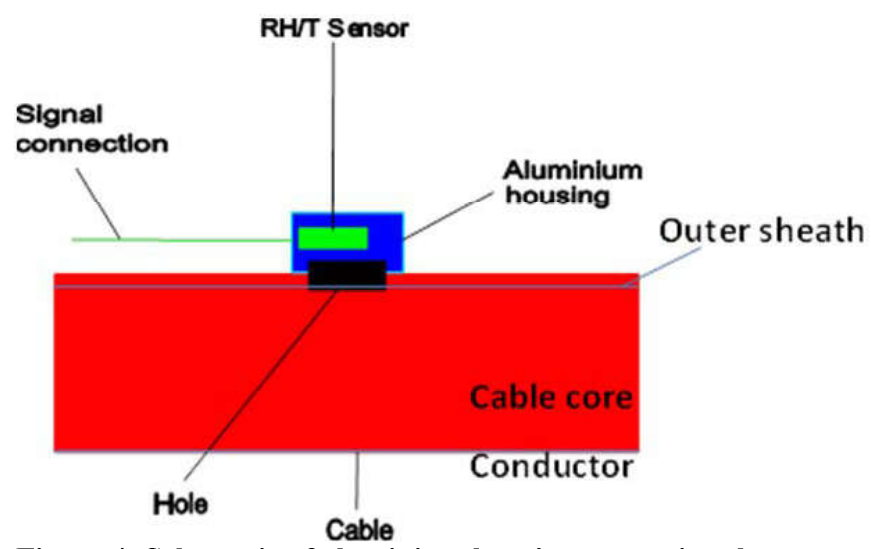

Figure 4: Schematic of aluminium housing protecting the relative humidity and temperature sensor with cable connection to be sealed with glue, additional aluminium tape towards the cable surface hole and heat shrinkable glue tubing.

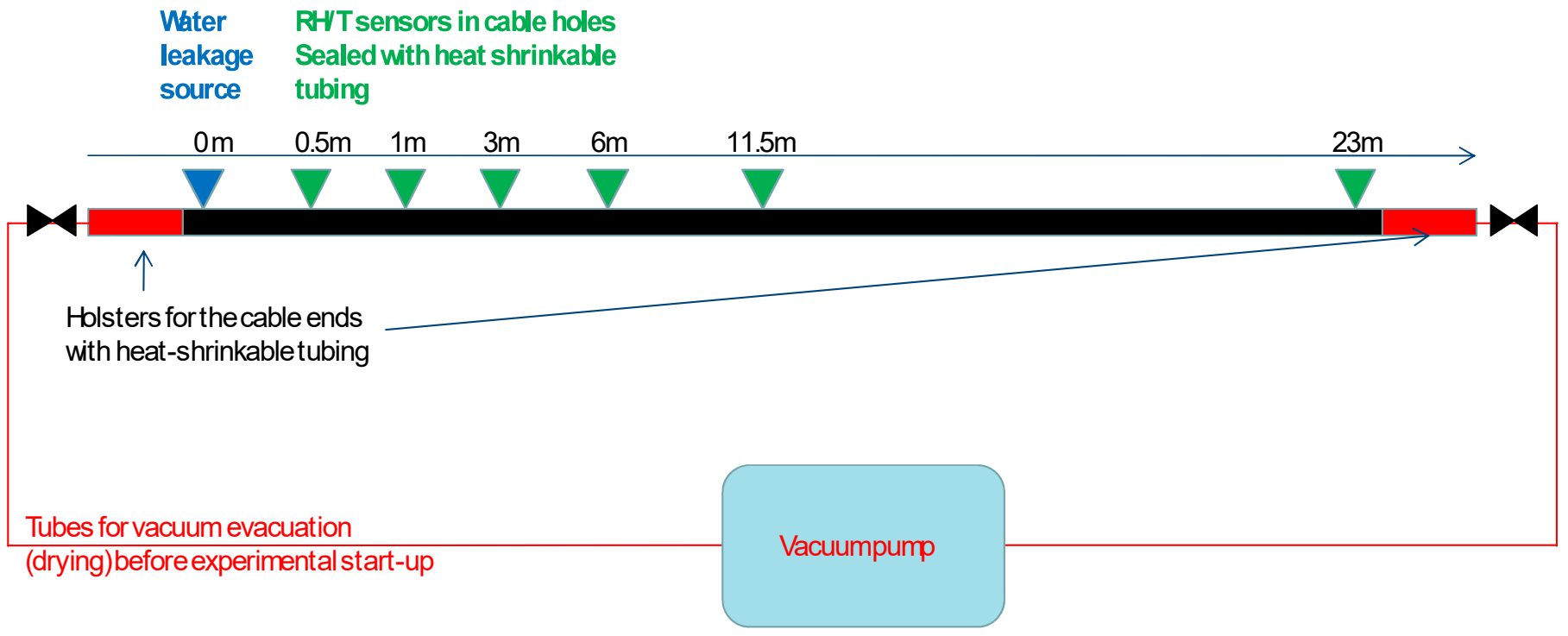

Figure 5: Experimental setup for axial water ingress. The water source is located at $0 \mathrm{~m}$ and $\mathrm{RH}$ and temperature sensors at different positions. 
Table 3 Relative Humidity (RH) before liquid water leakage

\begin{tabular}{|c|c|c|}
\hline $\begin{array}{l}\text { Sensor } \\
\text { Position }\end{array}$ & $\begin{array}{c}\text { RH } \\
(\%) \\
\text { Before } \\
\text { evac. }\end{array}$ & $\begin{array}{c}\text { RH (\%) } \\
\text { after } \\
\text { evac. }\end{array}$ \\
\hline $0.5 \mathrm{~m}$ & - & 21.4 \\
\hline $1.0 \mathrm{~m}$ & - & 27.1 \\
\hline $3.0 \mathrm{~m}$ & - & 30.0 \\
\hline $6.0 \mathrm{~m}$ & - & 34.5 \\
\hline $11.5 \mathrm{~m}$ & 59.2 & 33.8 \\
\hline $23.0 \mathrm{~m}$ & - & 27.9 \\
\hline Amb.1 & - & 55.0 \\
\hline Amb. 2 & - & 55.0 \\
\hline
\end{tabular}

\section{Experimental and Numerical results}

In Figure 6 the calculations in Comsol calculations are plotted for 3 different cases defined in the numerical modelling part [3-5] (table 2, cases 1-3) using the measured width of the swelling tape and air gap (figure 3). In case no. 1 the assumption was made that there is only air $(0.66 \mathrm{~mm})$ and no swelling tape, in case no. 2 that there is no air gap and only swelling tape $(0.66 \mathrm{~mm})$ and in case no. 3 the measured dimensions of the swelling tape $(0.22$ $\mathrm{mm})$ and air gap $(0.44 \mathrm{~mm})$ width was used as input for the model calculations.

Figure 6 shows that the axial diffusion of water vapour along the cable take place in the air gap and then it diffuses radial into the swelling tape. With swelling tape only very little water vapour diffuses axially into the cable. The measured increase in the relative humidity for the different sensors along the cable are shown in Figure 7, together with the

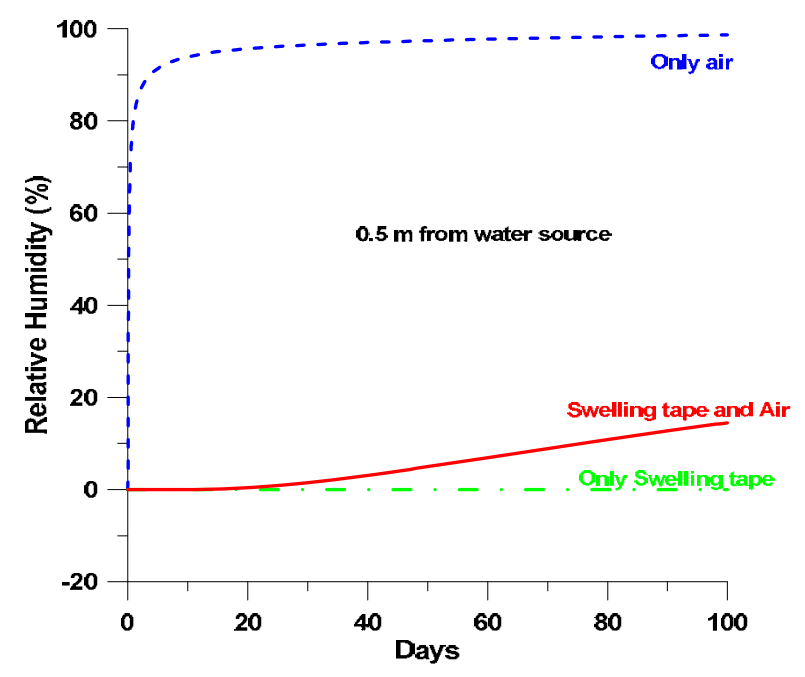

Figure 6: Numerical calculations of the increase in relative humidity at $0.5 \mathrm{~m}$ from the water source with only swelling tape $(0.66 \mathrm{~mm})$, only air $(0.66 \mathrm{~mm})$ and the combined measured dimensions of the air gap $(0.44$ $\mathrm{mm})$ and the swelling tape $(0.22 \mathrm{~mm})$ together.

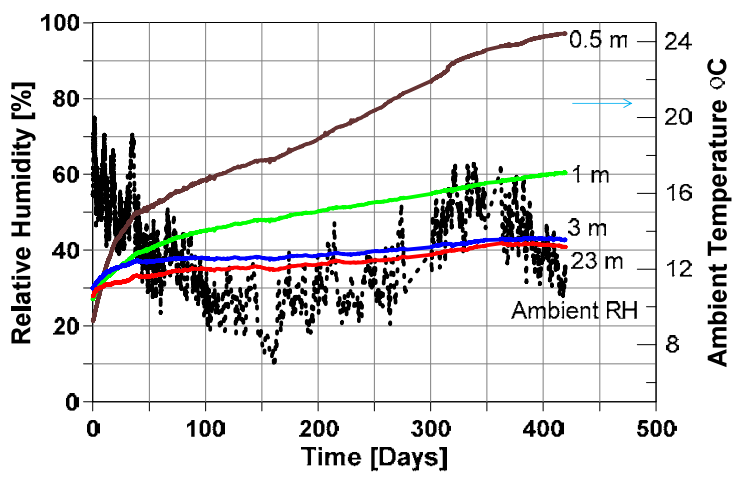

Figure 7: Relative humidity sensors development in the cable plotted together with the ambient relative humidity and temperature.

ambient temperature and relative humidity. It can be observed that the RH sensor at $0.5 \mathrm{~m}$ from the water source is very much affected (initial value of $21.4 \%$ ) and the sensor at $1 \mathrm{~m}$ also shows a significant increase. The changing ambient relative humidity also can be observed. For the other sensors it was not observed any significant effect of the water source after 430 days. The other sensors are not much affected by the axial water transport and their small increases in relative humidity are probably caused by diffusion of the ambient humidity in general through the glued aluminium laminate section in the cable and also through the holes where the sensors are positioned. Drift of the sensors could also be possible.

The swelling time for the swelling tapes was not known. Therefore we do not know where the water front will be located. In Figure 8 the measured relative humidity at $0.5 \mathrm{~m}$ is compared with a set of different possible positions of the water front (Table 2 , Case 4). The water source nominally is at $0.0 \mathrm{~m}$ but the water could propagate a significant distance along the cable swelling tape before the swelling take place. This propagation distance is unknown but the calculated relative humidity is shown for different liquid water positions.

There is a large difference between the model and the experiment when assuming that the water front is positioned at the water source. If we assume that the water front is located at $0.2 \mathrm{~m}$ from the sensor there is good agreement up to about 40 days (Figure 8). However the increase seems to saturate, and a larger deviation between the calculations and measurements occur. During vacuum evacuation the cable ends becomes dryer than the central parts. This difference will be equalised during the experiment affecting the relative humidity of all sensors. In addition the sealing around the sensors are likely not completely watertight (vapour) as an increase in relative humidity of these sensors is observed. 


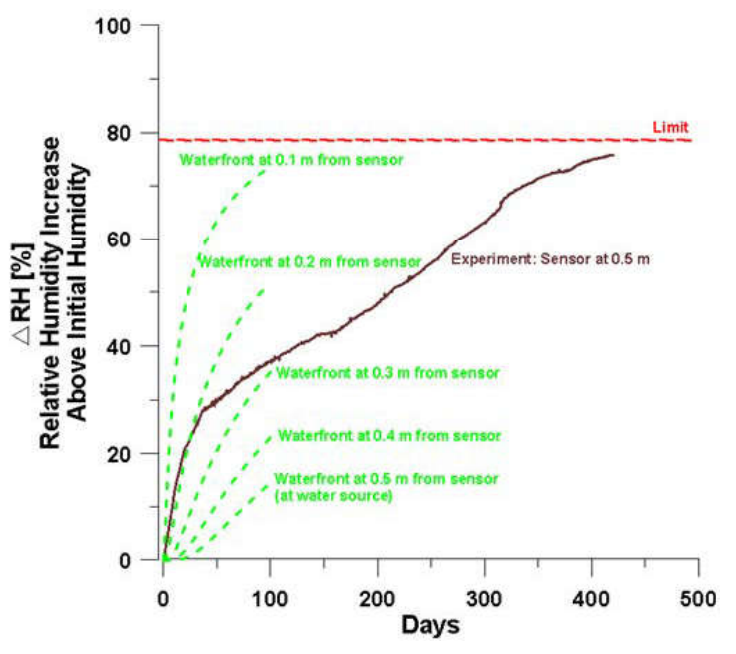

Figure 8: Sensitivity numerical analyses with the water front (at a different position than the water source) as parameter compared with the experiment measurement at $0.5 \mathrm{~m}$.

\section{Conclusions and Further work}

In general the results show that it takes a long time for the water vapour to penetrate axially along the cable. After 430 days the relative humidity at $0.5 \mathrm{~m}$ from the liquid water source increased to about $75 \%$. It was not possible to observe any significant change (caused by the water source) in relative humidity $3 \mathrm{~m}$ and longer distances from the water source. The result gives an indication to the cable owners about the needed length of the cable to be cut when the outer sheath of the cable is damaged and water has entered the cable core.

After this experiment has ended the actual position of the water front will be verified. The real dimensions of the swelling tape and the air gap at the water front also will be measured. There is also not enough data about the diffusion and solubility coefficients of this particular swelling tape and the model needs to be improved from a geometrical point of view. The semiconductor in the cable could also influence the water absorption in the cable. Finally the atmosphere where the experiment takes place would also influence since the sealing are not completely watertight.

\section{Acknowledgment}

SINTEF Energy Research and NEXANS Norway acknowledge the Norwegian Research Council for their support in the BIP project No. 208536 "SmartPEX".

\section{References}

[1] E. Ildstad and H. Faremo, Importance of Relative Humidity on Water Treeing in XLPE Cable Insulation, ISH 91, Dresden August 1991.

[2] J. Crank and G.S. Park, "Diffusion in polymers". Academic Press, ISBN 0-12197050-7,1968.

[3] S. Nordås, S.M. Hellesø and S. Hvidsten, Measurements and Modelling of Water Diffusion in Water Blocking Tapes for High Voltage Extruded Cables, Proceedings of 2008 International Symposium on Electrical Insulating Materials ISEIM, pp 263-266, ISBN 9784886860064.

[4] S.M. Hellesø, V.C. Henøen and S. Hvidsten, Simulation of Water Diffusion in Polymeric Cables Using Finite Element Methods, Conference record of the 2008 IEEE International Symposium on Electrical Insulation, Vancover, ISBN 9781454420926.

[5] S. M. Hellesø, S. Hvidsten, G. Balog and K.M. Furuheim, Calculation of Water Ingress in a $\mathrm{HV}$ Subsea XLPE Cable with a Layered Water Barrier Sheath System, DOI 10.1002/app.33568, Journal of Applied Polymer Science, Vol. 121, 2127-2133 (2011), 2011 Wiley Periodicals, Inc.

[6] K. B. Liland, S. M. Hellesø, S. Hvidsten. K. M. Bengtsson and $\mathrm{A}$. Ryen, Axial Water Ingress in Watertight MV XLPE Cable Designs, Electrical Insulation (ISEI), Conference Record of the 2012 IEEE International Symposium, Puerto Rico 10-13 June 2012. DOI 10.1109/ELINSL.2012.6 